STUDI

FRANCESI

\section{Studi Francesi}

Rivista quadrimestrale fondata da Franco Simone

185 (LXII | II) | 2018

OCTAVE MIRBEAU: UNE CONSCIENCE AU TOURNANT

DU SIEECLE - sous la direction de Ida Merello

\title{
GUILLAUME CUCHET, Penser le christianisme au XIX siècle. Alphonse Gratry (1805-1872)
}

\section{Michel Arrous}

\section{(2) OpenEdition \\ Journals}

Édition électronique

URL : https://journals.openedition.org/studifrancesi/13827

DOI : 10.4000/studifrancesi. 13827

ISSN : 2421-5856

Éditeur

Rosenberg \& Sellier

Édition imprimée

Date de publication : 1 août 2018

Pagination : 342-343

ISSN : 0039-2944

\section{Référence électronique}

Michel Arrous, « guillaume cuchet, Penser le christianisme au xix siècle. Alphonse Gratry (1805-1872) 》, Studi Francesi [En ligne], 185 (LXII | II) | 2018, mis en ligne le 01 août 2018, consulté le 15 novembre 2021. URL : http://journals.openedition.org/studifrancesi/13827 ; DOI : https://doi.org/10.4000/ studifrancesi. 13827

Ce document a été généré automatiquement le 15 novembre 2021.

\section{(c)}

Studi Francesi è distribuita con Licenza Creative Commons Attribuzione - Non commerciale - Non opere derivate 4.0 Internazionale. 


\title{
GUILlaume CUCHET, Penser le christianisme au XIX ${ }^{e}$ siècle. Alphonse Gratry (1805-1872)
}

\author{
Michel Arrous
}

\section{RÉFÉRENCE}

GUILlaUme CUCHET, Penser le christianisme au XIX siècle. Alphonse Gratry (1805-1872). “Journal de ma vie" et autres textesXIX ${ }^{\mathrm{e}}$, Presses Universitaires de Rennes, 2017, 325 pp.

1 Avez-vous lu l'abbé Gratry? La question embarrassera plus d'un dix-neuviémiste. Dans l'introduction à son important essai biographique (pp.15-89) qui précède cette anthologie, Guillaume Cuchet regrette qu'on ait oublié l'un des penseurs religieux les plus importants et les plus lus du Second Empire. Cette éminente figure de l'apostolat intellectuel ad extra aurait pu être le théologien que le catholicisme «libéral» attendait. Son œuvre apologétique, qui eut pour origine une révélation vécue à l'adolescence, doit être située dans la philosophie chrétienne du XIX siècle. Sont retracées les grandes étapes d'une vie consacrée à l'«unité de la bergerie universelle»: une jeunesse libérale sous la Restauration, l'École polytechnique (1825-1827), la participation, de 1828 à 1840, à une expérience de vie communautaire à Strasbourg (ordination en 1833) auprès du philosophe et abbé Louis Bautain (ce disciple de Cousin s'était converti) et sous l'influence d'une mystique, puis, jusqu'en 1846, la direction du collège Stanislas qu'il laissa pour l'aumônerie de l'École normale. En 1848, dans son Catéchisme social (réédité en 1871 sous le titre Les Sources de la régénération sociale), il préconisait une politique de «progrès social» pour réduire le "paupérisme», tout en critiquant le socialisme. Si ce premier ouvrage passa inaperçu, ce ne fut pas le cas en 1851 de sa participation, sur l'incitation de Dupanloup, à l'offensive contre Vacherot, le directeur des études à l'École normale qui avait été déjà ciblé pour son hétérodoxie. Gratry se lança dans la polémique, appuyé par Veuillot, pour dénoncer les thèses historico-théologiques et 
l'athéisme de Vacherot, lequel fut révoqué. L'année suivante, il contribua à la résurrection de l'Oratoire, une congrégation conçue, selon ses dires, comme «une sorte de Port-Royal moins le schisme et l'orgueil»; mais, entre 1857 et 1861, le climat se dégrada sensiblement et le P. Gratry dut quitter l'Oratoire en août 1870. Catholique «libéral», ami de Dupanloup et de Montalembert, il s'engagea dans la «Ligue internationale et permanente de la Paix» pour soutenir la cause du pacifisme (après les horreurs de la guerre de Crimée) et de l'union des chrétiens, ce qui lui valut la défaveur d'une partie de l'opinion catholique. Sa situation s'aggrava en 1870, alors que débutait le concile Vatican I, quand il intervint, à la demande de Dupanloup, assez tardivement mais radicalement dans la controverse de la définition de l'infaillibilité. Ses prises de position anti-infaillibilistes firent de lui un des opposants les plus en vue et un suspect condamné par plus de quatre-vingts évêques, d'où son exclusion de l'Oratoire. Finalement, il se rallia publiquement à la définition.

2 Les chapitres II et III présentent l'œuvre philosophique et sa réception. Son ouvrage le plus important est De la Connaissance de Dieu (1853, réédité en 1854, 1856, 1864, traduit en allemand en 1858), premier volet d'une trilogie complétée en 1855 par la Logique et, en 1857, par De la Connaissance de l'âme (quatre éditions, traduit en allemand en 1858). On ajoutera Les Sources (1861-1862), publication destinée aux jeunes gens et qui eut un succès posthume (F. Mauriac le lisait à dix-huit ans, de même R. Rémond en 1930), ainsi que les conférences réunies dans Crise de la foi (1863). S'inspirant de Thomas d'Aquin et de Fénelon, l'abbé Gratry s'en prend à Hegel et aux hégéliens, ou à ceux qu'il assimile aux hégéliens (Renan, Vacherot, Scherer), autant de sophistes à ses yeux, et au scepticisme contemporain qu'il dénonce comme un «abaissement de la raison [qui] est le plus grand danger du christianisme». Aucun des débats de l'époque ne lui fut étranger. Il s'est exposé aux reproches de Ravaisson et de Scherer, mais il a eu aussi des partisans enthousiastes, tels Mme Swetchine, Falloux, Barbey et, hors du monde catholique, Guizot et Ernest Naville. Ajoutons que d'autres le regardaient avec méfiance: dans une lettre à Mérimée, qui le voyait en père Fatutto, «très poli et onctueux» et le rangeait dans les "animaux», Sainte-Beuve, lors de l'élection de Gratry à l'Académie française en 1868, dit de lui que c'est «un homme qui porte écrit sur son front: Je crois à l'Immaculée Conception». Son œuvre eut bien sûr peu d'écho dans le monde universitaire français où l'on se souvenait de son attaque contre Vacherot. Ces résistances n'ont pas empêché le succès du gratrysme dans les années 1857-1858. Certes, tout un pan de l'œuvre de ce penseur du christianisme est obsolète; néanmoins, le P. Gratry reste un «témoin éclairant de l'esprit du XIX siècle». Aussi lira-t-on dans la deuxième partie, avec un vif intérêt, la version intégrale du Journal de ma vie (pp. 91-171): rédigé en 1854 et relu en 1867, ce texte est en fait une autobiographie spirituelle qui connut en France, où il fut publié en 1874 dans une version partielle et expurgée, de nombreuses rééditions jusqu'en 1917. Dans l'anthologie (troisième partie), figurent de nombreux extraits de Crise de la foi, de la Philosophie du credo (1861), de la Logique (édition de 1858) et de La Morale et la loi de l'histoire (1868), sur l'avenir de la foi dans la société moderne, la philosophie «matérialiste» de l'histoire (i.e. «au point de vue de l'athéisme et du matérialisme contemporains»), l'athéisme «réel» et l'athéisme «apparent» («Tout homme qui maintient la morale, lors même qu'il se déclare athée, n'est pas athée dans l'âme. Il est inconséquent, il est absurde, c'est évident; mais ce n'est pas un monstre»). Dans cette quarantaine de textes, on signalera aussi, et plus particulièrement, la lettre de 1856 à l'archevêque de Paris sur la conversion d'Augustin Thierry, une analyse de l'itinéraire spirituel de Maine de Biran (pp. 247-259) ou des 
considérations sur «l'âge où l'homme arrive au milieu de ses jours» (pp. 292-294). On regrettera l'absence d'extraits de la Lettre à M. Vacherot rééditée sous le titre Une Étude de la sophistique contemporaine ou Lettre à M. Vacherot, ainsi que des Lettres sur la religion. Réponse à M. Vacherot (publiées en volume en 1869), dans lesquelles Gratry réplique à «La théologie catholique en France», article de Vacherot dans la «Revue des deux mondes» en 1868.

3 Souhaitons que ce riche volume de la collection «Histoire religieuse de la France» suscite un nouveau lectorat au P. Gratry dont on s'est demandé lors d'un récent colloque s'il était «marginal ou précurseur». Enfin, nous permettra-t-on une pointe? Contrairement à ce qui est rapporté (p. 71), on peut légitimement penser que le confesseur d'Augustin Thierry n'a pas eu la même réussite auprès de Mérimée qui, in extremis, préféra la confession d'Augsbourg. 